\title{
Experimental study of pre- and postnatal caffeine exposure and its observable effects on selected neurotranmitters and behavioural attributes at puberty
}

Joshua Owolabi ( $\sim$ jowolabi@ughe.org )

University of Global Health Equity https://orcid.org/0000-0003-2880-9701

Adefule Kehinde

Olabisi Onabanjo University

Philemon Shallie

Olabisi Onabanjo University

Oluseyi Fabiyi

Babcock University

Sunday Olatunji

Babcock University

John Olanrewaju

Babcock University

Testimony Ajibade

Babcock University

Samson Oyewumi

Babcock University

Philip Ogunnaike

Babcock University

\section{Research Article}

Keywords: Brain, Neurotransmitters, Caffeine, Neurobehaviour, Memory

Posted Date: May 7th, 2021

DOI: https://doi.org/10.21203/rs.3.rs-278073/v1

License: (c) (i) This work is licensed under a Creative Commons Attribution 4.0 International License. Read Full License 


\section{Abstract}

Caffeine is globally consumed as a stimulant in beverage drinks; it is also ingested in purified forms as power and tablets. Concerns have been raised about the potential consequences of intrauterine and early life caffeine exposure on brain health. This study modeled caffeine exposure during pregnancy and early postanal life until puberty, and the potential consequences. Caffeine powder was dissolved in distilled water. Thirty-two $(n=32)$ pregnant mice (Mus musculus) were divided into four groups- $A, B, C$ and $D$. Group $A$ animals served as a control, receiving placebo. Caffeine doses in $\mathrm{mg} / \mathrm{kg}$ body weight were administered as follows: Group B, $10 \mathrm{mg} / \mathrm{kg}$; Group C, $50 \mathrm{mg} / \mathrm{kg} ;$ Group D, $120 \mathrm{mg} / \mathrm{kg}$. Prenatal caffeine exposure [phase I] lasted throughout pregnancy. Half the number of offspring were sacrificed at birth; the rest were recruited into phase II and the experiment continued till day 35, marking puberty. Brain samples were processed following sacrifice. $\gamma$-aminobutyric acid (GABA), acetylcholine (ACh), and serotonin (5Ht) neurotransmitters were assayed in homogenates to evaluate functional neurochemistry. Anxiety and memory as neurobehavioural attributes were observed using the elevated plus and Barnes' mazes respectively. Continuous caffeine exposure produced positive effects on short and long-term memory parameters; the pattern interestingly was irregular and appeared more effective with the lowest experimental dose. Anxiety test results showed no attributable significant aberrations. Caffeine exposure persistently altered the neurochemistry of selected neurotransmitters including $\mathrm{ACh}$ and $5 \mathrm{Ht}$, including when exposure lasted only during pregnancy. ACh significantly increased in group $\mathrm{B}^{\mathrm{C}+}$ to $0.3475 \mu \mathrm{gg}^{-1}$ relative to control's $0.2508 \mu \mathrm{gg}^{-1}$; pre-and continuous postnatal exposure in Group B increased $5 \mathrm{Ht}$ to $0.2203 \mu \mathrm{gg}^{-1}$ and $0.2213 \mu \mathrm{gg}^{-1}{ }^{-1}$ respectively relative to control's $0.1863 \mu \mathrm{gg}^{-1}$. From the current investigation, caffeine exposure in pregnancy had persistent effects on brain functional attributes including neurotransmitters activities, memory and anxiety. Caffeine in moderate doses affected memory positively but produced negative effects at the higher dosage including increased anxiety tendencies.

\section{Background}

Caffeine exerts its effects on the brain primarily by blocking the Adenosine $A_{1}$ and $A_{2 A}$ receptors. The blocking effects of caffeine on adenosine receptors produce secondary effects on several neurotransmitters especially noradrenalin, dopamine, serotonin, acetylcholine, glutamate as well as GABA (Daly 1993). It has been observed that caffeine could accumulate in the brain over time during development (Li et al. 2012; Tanaka, et al. 1987). In the report of Li et al. (2012), caffeine metabolites are naturally decreased in the pregnant mother by natural biological mechanisms; the inability to metabolize caffeine results in caffeine build-up over time and this also relates to disruption of neurotransmitter signals which may affect development through organogenesis and growth in the third trimester of humans. Another report stated that caffeine retarded brain development when administered around puberty in rat supposedly by reducing optimal synaptic development (Olini et al. 2013). This effect was said to have been associated with sleep reduction caused by caffeine (Olini et al. 2013). 
Castellanos and Rapoport (2002) in their review article concluded that caffeine effects in children were modest and harmless. It has also been reported by Ådén et al. (2000) that low dose of caffeine ingestion during gestation and postnatal life produced minor effects on development of adenosine $A_{1}$ and $A_{2 A}$ receptors and $G_{A B A}$ receptors in the rat brain. In humans. Nehlig et al. (1992) reported that the effects of caffeine on learning, memory, performance and coordination are rather related to the methylxanthine action on arousal, vigilance and fatigue. Caffeine exerts obvious effects on anxiety and sleep which vary according to individual sensitivity to the methylxanthine. Children in general do not appear more sensitive to methylxanthine effects than adults. Also, the central nervous system does not seem to develop a great tolerance to the effects of caffeine although dependence and withdrawal symptoms are reported.

Caffeine influences mood, and a dose of about $3.0 \mathrm{mg} / \mathrm{kg}$ body weight of caffeine has been associated with positive subjective effects (Daly, 1993). Such effects reportedly made subject energetic, creative, efficient, self-confident, alert, motivated, focused on tasks with an accompanying willingness to socialize (Fredholm et al. 1999; Griffiths et al. 1990; Silverman et al. 1994; Griffiths and Mumford 1995). Kenemans and Lorist (1995) stated that caffeine effects include increase of cortical activation which is the rate at which information about the stimulus accumulates selectivity particularly with regard to further processing of the primary attribute as well as rates of motor processes via central and/or peripheral mechanisms. Caffeine interactions with the brain, especially in adults, have been found to produce interesting behavioural effects including self confidence, positive attitude and talkativeness (Griffiths and Mumford, 1995). Caffeine tolerance (Fredholm et al. 1999) and dependence (Griffiths et al. 1986; Silverman et al. 1992; Strain et al. 1994; Hughes and Hale, 1998; Hughes et al. 1998; Bernstein et al. 2002); though certain sources tend to express caution with respect to the use of these terms due to the high non-drug social acceptance of caffeine and the wide range of effects that it could produce on various people (Kendler and Prescott 1999; Alsene et al. 2003; Temple 2009).

It is very important to note that most human subject studies on caffeine consumption have been conducted on adults' brains and behaviours (Temple 2009). Hence several caffeine-safety-for- all reports might have been obtained from adult studies. Concerns have been raised on whether caffeine is equally safe for consumption at all life stages (Temple 2009). Children and adolescents have increasingly consumed caffeine-containing substances (Harnack et al. 1999).

Relative to body weight, children and adolescents might often consume more caffeine than adults (Frary et al. 2005; Temple 2009). Some of the studies on children and adolescents suggested that caffeine could produce long term effects on young habitual consumers. Certain effects of caffeine in children are similar to those that occur in adults (Temple 2009). Moderate to high caffeine dosages of about 100$400 \mathrm{mg}$ have been associated with behavioural effects including increased alertness, jitteriness, nervousness and fidgetiness (Elkins et al. 1981; Rapoport et al. 1984; Bernstein et al. 1994). In addition to these are other adult related effects including withdrawal effects (Hale et al 1995; Bernstein et al. 2001) and rise in ambulatory blood pressure (Savoca et al. 2004; Savoca et al. 2005). This study is very important as it was estimated that as many as $80 \%$ of women consume caffeine throughout pregnancy. The American College of Obstetricians and Gynecologists (2010) had recommended caffeine 
consumption dose limit of less than $200 \mathrm{mg} / \mathrm{kg}$ body weight per day for preganat women (ACOG, 2010). This study is also one of the very few research efforts to experimentally model caffeine consuption across human lifespan from the start of preganacy up until puberty.

\section{Materials And Methods}

\section{Caffeine Preparation and Administration}

Pure anhydrous caffeine was used for the investigation. It was obtained from Powder City, York USA; labelled as dietary supplement caffeine anhydrous with Batch Number 151219 and Lot Number CAFAH20151012. It was dissolved in distilled water to produce the experimental doses that were orally administered to the animal groups. The anhydrous caffeine powder was dissolved in distilled water at room temperature.

\section{Experimental Animals- Housing, Handling and Treatment}

Housing space was designed based on Fawcett (2012b) recommendation. Caging, handling of adult mice and neonates, routine husbandry procedure, laboratory environment, environmental enrichment, feeding and drinking water supply as well as monitoring of the animals were done in line with the recommendations of Fawcett (2012c). Adequate laboratory space and proper ventilation helped to maintain a suitable room temperature. Handling was minimized, only when necessary and generally and done with care bearing in mind that handling neonates could produce effects that might persist throughout the animal's life (D'Amore et al. 1995). Generally, animals were treated, observing proper ethical guidelines.

\section{Overview of Research Design}

Thirty-two ( $\mathrm{n}=32$ ) adult female pregnant mice (Mus musculus), of approximately same age (60 days old) and $21 \mathrm{~g}$ average body weight were used primarily for the research. They were divided into four groups labelled A, B, C and D which included the Control, Low-Dose, Medium-Dose and High-Dose groups respectively. The Phase II (postnatal development stage) of the investigation included the remaining offspring (minus the ones sacrificed at the end of Phase I). In the Phase II, the $\mathrm{B}^{\mathrm{C}-}, \mathrm{C}^{\mathrm{C}^{-}}$and $\mathrm{D}^{\mathrm{C}-}$ animal groups represent the animal that were only subjected to prenatal caffeine treatment through their mothers but afterwards allowed to develop till puberty without caffeine administration so as to observe the possibility of persistence of caffeine prenatal effects. Also, the $\mathrm{B}^{\mathrm{C}+}, \mathrm{C}^{\mathrm{C}+}$ and $\mathrm{D}^{\mathrm{C}+}$ represented animals that were continuously exposed to cafiine until the end of experiment. To achieve the objective of Phase $\mathrm{II}$, animals that continued with caffeine exposure had caffeine administered to their mothers unitl they were weaned about day 25, postnanal; after which they received caffine through the oral gavage till day 35 [Table 1]. 
Table 1

Experimental Animal Grouping, Dosages and Rationale

\section{Phase I}

\begin{tabular}{|c|c|c|c|c|}
\hline Grouping & Animals & Dosage & Description & Rationale \\
\hline Group A & 8 & Control & $\begin{array}{l}\text { No caffeine treatment; animals received a } \\
\text { placebo of } 5 \% \text { sucrose solution }\end{array}$ & \\
\hline Group B & 8 & $\begin{array}{l}10 \mathrm{mg} / \mathrm{kg} \\
\text { body weight }\end{array}$ & $\begin{array}{l}\text { Lower caffeine dosage was administered to } \\
\text { pregnant animals }\end{array}$ & $\begin{array}{l}\text { Lower dose } \\
\text { treatment }\end{array}$ \\
\hline Group C & 8 & $\begin{array}{l}50 \mathrm{mg} / \mathrm{kg} \\
\text { body weight }\end{array}$ & $\begin{array}{l}\text { Medium caffeine dosage was administered } \\
\text { to pregnant animals }\end{array}$ & $\begin{array}{l}\text { Medium } \\
\text { dose } \\
\text { treatment }\end{array}$ \\
\hline Group D & 8 & $\begin{array}{l}120 \mathrm{mg} / \mathrm{kg} \\
\text { body weight }\end{array}$ & $\begin{array}{l}\text { High caffeine dosage was administered to } \\
\text { pregnant animals }\end{array}$ & $\begin{array}{l}\text { High dose } \\
\text { treatment }\end{array}$ \\
\hline \multicolumn{5}{|l|}{ Phase II } \\
\hline Grouping & Animals & Dosage & Rationale & \\
\hline Group A & 8 & Control & & \\
\hline $\begin{array}{l}\text { Group B } \\
\mathrm{C}+\end{array}$ & 8 & $\begin{array}{l}10 \mathrm{mg} / \mathrm{kg} \\
\text { body weight }\end{array}$ & $\begin{array}{l}\text { Lower caffeine dosage was administered to } \\
\text { offspring }\end{array}$ & $\begin{array}{l}\text { Lower dose } \\
\text { treatment }\end{array}$ \\
\hline $\begin{array}{l}\text { Group } \\
\mathrm{B}^{\mathrm{C}^{-}}\end{array}$ & & No treatment & & \\
\hline $\begin{array}{l}\text { Group C } \\
\text { C+ }\end{array}$ & 8 & $\begin{array}{l}50 \mathrm{mg} / \mathrm{kg} \\
\text { body weight }\end{array}$ & $\begin{array}{l}\text { Medium caffeine dosage was administered } \\
\text { to offspring }\end{array}$ & $\begin{array}{l}\text { Medium } \\
\text { dose } \\
\text { treatment }\end{array}$ \\
\hline $\begin{array}{l}\text { Group C } \\
\mathrm{C}^{-}\end{array}$ & & No treatment & & \\
\hline $\begin{array}{l}\text { Group D } \\
\mathrm{C}^{+}\end{array}$ & 8 & $\begin{array}{l}120 \mathrm{mg} / \mathrm{kg} \\
\text { body weight }\end{array}$ & $\begin{array}{l}\text { High caffeine dosage was administered to } \\
\text { offspring }\end{array}$ & $\begin{array}{l}\text { High dose } \\
\text { treatment }\end{array}$ \\
\hline $\begin{array}{l}\text { Group D } \\
\mathrm{C}^{-}\end{array}$ & & No treatment & & \\
\hline
\end{tabular}

\section{Treatment of Experimental Animals}

Low dose: $10 \mathrm{mg} / \mathrm{kg}$ body weight

The low dose was equivalent to taking about 2-3 cups of coffee/tea per day or 2-3 coffee tablets or chewing 2-3 bar of caffeine-containing chocolate or equivalent in humans based on a metabolic body weight conversion (Soellner et al. 2009). This would represent habitual mild, yet regular consumption of caffeine in coffee, tea or other sources such as in caffeinated drinks or in form of pills. This is a precaffeinism level of consumption which may not induce caffeinism or caffeine dependency. 
This was equivalent to taking about 10-15 cups of coffee/tea per day or 5 coffee tablets or chewing 5 bars of caffeine-containing chocolate or equivalent (Soellner et al. 2009).

This represented habitual caffeine consumption and dependency; it is often marking a mild level of caffeinism in individuals who routinely consume coffee or caffeinated drinks on daily basis as well as people who deliberately consume caffeine pills to increase alertness, increase activity rate or enhance productivity and usually making it a way of life.

High dose: $120 \mathrm{mg} / \mathrm{kg}$ body weight

This was equivalent to taking above 20 cups of coffee per day or 20 coffee tablets or chewing 20 bars of caffeine-containing chocolate or equivalent (Soellner et al. 2009). This represented abnormal coffee consumption and a high level of addiction with associated serious health risks.

\section{Neurobehavioural Studies}

Neurobehavioural assay tools and protocols were used to study learning and memory. These included the Barnes maze as well as the elevated plus maze. The use of neurobehavioural tools helped to evaluate specific mental attributes that might be correlated with memory, learning, cognition and personality in humans. Selected mental attributes that were evaluated in the animals included anxiety, learning and memory.

The Elevated Plus Maze for the Test of Anxiety-Related Behaviour (Walf and Frye, 2007; Komada, Takao and Miyakawa, 2008)

The elevated plus maze is a popular neurobehavioural tool for rodents to study anxiety-related behaviour (Walf and Frye 2007). Procedure began by preparing the maze by cleaning, drying and setting the videotracking device. Data sheets were prepared appropriately based on grouping and other experimental design parameters. Mice were introduced into the behavioural testing room. Experiment started by placing mice at the junction of the open and closed arms, facing the open arm opposite to where the experimenter is. Mice monitoring and data collection was done using the video-tracking device and timer, set for 5-minute time blocks for the mice on the maze. Data analyses and interpretation were done using suitable statistical tools and software to analyse collected data with respect to the following major parameters: (a). open arm time (b) closed arm time (c) open arm entries made (d) closed arm entries made (e) total entries made (f) The ratio of open or closed arm entries/time to the total arm entries/time (to observe differences between groups in the general motor activity in the maze). Appropriate inferences were obtained from analysed data.

The Barnes Maze for Testing Spatial Reference Memory in the Mice (Barnes, 1979; Sunyer et al., 2007). 
Barnes maze consists of a circular platform ( $92 \mathrm{~cm}$ diameter) elevated $105 \mathrm{~cm}$ above the floor with 20 equally spaced holes ( $5 \mathrm{~cm}$ diameter; $7.5 \mathrm{~cm}$ between holes). To achieve adaptation, each mouse was placed in a cylindrical black start chamber in the middle of the maze. The chamber was removed after 10 s stimulus was initiated. Mouse was guided gently to the escape box. Stimulus was stopped once the mouse was inside the escape box and the mouse was allowed to stay in the escape box for 2 min. To achieve spatial acquisition: maze was cleaned with $1 \%$ incidin solution to avoid olfactory cues. Mouse was placed in the black start chamber in the middle of the maze and released after 10s with stimulus initiated. Within 3 minutes, the number of primary errors, total errors and primary latency were recorded. Trial ended once the mouse entered the goal tunnel or after 3 minutes. If the mouse did not reach the goal within 3 minutes, it was guided gently to the escape box and left inside for 1 minute. Mouse was removed from the escape box and returned to the holding cage until the next trial. Training was repeated until each mouse had had the desired number of trials for the day. (Animals could receive 4 trials per day with an inter-trial interval- ITI of 15 minutes during 4 days).

To test for the reference memory (short- and long-term retention probe trial): Probe trial was conducted on day 5, 24 hours after the last training day. The target hole was closed and the maze was rotated and readjusted, so that the holes are in the same position as during the training days. In each case, a mouse was positioned, and stimulus was initiated. The mouse was allowed to explore the maze. Mouse was removed after a fixed interval; the probe trial was done in order to determine if the animal remembered where the target goal was located. Number of pokes (errors) in each hole and latency and path length to reach the virtually target hole were recorded. To assess long-term retention a second probe trial was applied on day 12, without any training session between day 5 and day 12; repeating the basic steps. Data collection and analysis was done statistically using the Graphpad prism.

\section{Collection and Preparation of Tissues for Biochemical Assay Procedures}

Adult animals were sacrificed by cervical dislocation. The brain cortex after careful excision was homogenised in $10 \%$ sucrose. The homogenates' supernatant was used as samples for specific neurtranmsitters biochemical assays.

\section{Neurotransmitters' Analyses}

Neurotransmitters' assays provided information on neuronal functions. Freshly dissected and properly excised brain cortex samples were weighed using the digital Ohaus $₫$ DV314C and homogenised in equal volumes of $10 \%$ sucrose. The homogenates were used as samples for specific assays of neurotransmitters. Table 2 shows the rationale for neurotransmitters assays. 
Table 2

Neurotransmitters' Studies and Rationale

\begin{tabular}{|c|c|c|c|}
\hline & Neurotransmitter & $\begin{array}{l}\text { Purpose of } \\
\text { Assay }\end{array}$ & Rationale \\
\hline 1 & Acetylcholine & $\begin{array}{l}\text { Neuronal } \\
\text { Activities }\end{array}$ & $\begin{array}{l}\text { Fuctional information on projection neurons especially of } \\
\text { basal nucleus of Meynert; which degenerates in Alzheimer's } \\
\text { disease use acetylcholine }\end{array}$ \\
\hline 2 & Serotonin & $\begin{array}{l}\text { Neuronal } \\
\text { activities } \\
\text { relative to } \\
\text { anxiety, } \\
\text { mood and } \\
\text { its disorders }\end{array}$ & $\begin{array}{l}\text { Serotonin (5-HT)) is an indolamine. The permissive } \\
\text { serotonin hypothesis states that when } 5-\mathrm{HT} \text { activity is } \\
\text { reduced, decreased levels of catecholamines cause } \\
\text { depression and insomnia; and when } 5-\mathrm{HT} \text { activity is } \\
\text { increased, elevated levels of catecholamines cause mania. } \\
\text { Dysfunction of 5-HT may underlie certain disrders including } \\
\text { obsessive-compulsive disorder. }\end{array}$ \\
\hline 3 & $\begin{array}{l}\text { GABA } \\
\text { (Y-Aminobutyric } \\
\text { acid) }\end{array}$ & $\begin{array}{l}\text { Evaluation } \\
\text { of } \\
\text { neurocortical } \\
\text { structural } \\
\text { and } \\
\text { functional } \\
\text { integrity }\end{array}$ & $\begin{array}{l}\text { GABA is the major inhibitory neurotransmitter of the brain; } \\
\text { hence it influences the functions of various important } \\
\text { cortical cells- stellate, basket, and Purkinje. }\end{array}$ \\
\hline
\end{tabular}

Acetylcholine Assay as a Measure of Neuronal Activities (Abcam, 2015)

Samples were prepared from homogenate supernatants. Reaction mix was added and incubated at room temperature for 30 minutes. Optical density $(O D=570 \mathrm{~nm})$ was measured or fluorescence (Ex/Em = $535 / 587 \mathrm{~nm}$ ). Standard choline probe was prepared: Acetylcholinesterase and enzyme mix (aliquot if necessary). Appropriate standard curve for the detection method of choice (colorimetric or fluorometric) was prepared. Samples were prepared in duplicate. Appropriate reaction mix were also prepared (based on Number samples + standards + 1) as follows: - Choline + AchE reaction mix; plate for standard was set up $(50 \mu \mathrm{L})$; samples $(50 \mu \mathrm{L})$ and background wells $(50 \mu \mathrm{L})$; and $50 \mu \mathrm{L}$ of appropriate reaction mix was added to wells. Plates were incubated at room temperature for 30 minutes and protected from light. Plates were measured at OD 570nm for colorimetric assay or $\mathrm{Ex} / \mathrm{Em}=535 / 587 \mathrm{~nm}$ for fluorometric assay.

\section{Serotonin ELISA}

Acylated standards, $100 \mu \mathrm{L}$ was pipettied, plus controls and samples into the appropriate wells of the serotonin/5-HIAA microtiter strips followed by pipetting $25 \mu \mathrm{L}$ of the serotonin antiserum into all wells. Plates were covered with adhesive foil and incubated for $15-20$ hours at $2-8^{\circ} \mathrm{C}$. The foil was removed, and the contents of the wells were discarded or aspirated. Each well was washed 3 times thoroughly by adding $300 \mu \mathrm{L}$ wash buffer. This was followed by discarding content and blotting dry each time by tapping the inverted plate on absorbent material. Next, $100 \mu \mathrm{L}$ of the enzyme conjugate was pipetted into all wells followed by incubating for $30 \mathrm{~min}$ at RT $\left(20-25^{\circ} \mathrm{C}\right.$ ) on a shaker (approx. $600 \mathrm{rpm}$ ). Discarding or aspirating the contents of the wells followed after which each well was washed 3 times thoroughly by adding $300 \mu \mathrm{L}$ wash wuffer. Content was discarded and blotted dry each time by tapping the inverted 
plate on absorbent material. $100 \mu \mathrm{L}$ of the substrate was pipetted into all wells and incubated for $20-30$ min at RT $\left(20-25^{\circ} \mathrm{C}\right)$ on a shaker (approx. $\left.600 \mathrm{rpm}\right)$. Further, $100 \mu \mathrm{L}$ of the stop solution was added to each well and the microtiter plate was shaken to ensure a homogeneous distribution of the solution. The absorbance of the solution in the wells was read within 10 minutes, using a microplate reader set to 450 $\mathrm{nm}$ and a reference wavelength between $620 \mathrm{~nm}$ and $650 \mathrm{~nm}$.

GABA Assay: Evaluation of Neurocortical Structural and Functional Integrity (Elisa, 2015)

All reagents, samples and standards were prepared. First, $50 \mu \mathrm{L}$ standard or sample was added to each well; then adding 50 $\mu$ Lprepared Detection Reagent A immediately, shaking and mixing; then incubating 1 hour at $37 \mathrm{oC}$. This was followed by aspirating and washing 3 times. $100 \mu \mathrm{L}$ prepared detection reagent $\mathrm{B}$ was added and incubated 30 minutes at $37^{\circ} \mathrm{C}$; followed by aspirating and washing 5 times. $90 \mu \mathrm{L}$ substrate solution wass added and followed by incubating 15-25 minutes at $37 \mathrm{oC}$. Finally, $50 \mu \mathrm{L}$ stop solution was added and followed by reading at $450 \mathrm{~nm}$ immediately.

\section{Quantitative Data Analysis: Statistical Methods}

Results from each study methods and tools were properly collated using data collection principles. Values were recorded for each measured parameter for each experimental animal and tabulated as such for each group. Mean values for parameters were obtained as well as the standard error of means. Bar charts were appropriately used to present values. Inferential statistics was carried out using the One-Way ANOVA Dunnett Method to evaluate statistical significance of values (means) especially relative to the Controls ( $P$ value $\leq 0.05$ ). The GraphPad Prism 5 version statistical software was used for statistical analysis.

\section{Results}

The Group D offspring that were exposed to high caffeine dosage during pregnancy all died a few days after birth; hence the results available for this Group $D$ included only those that were taken at birth. The offspring that received caffeine during pregnancy alone died about the same time that others that were continuously exposed to caffeine, postnatally, died. Neurotransmitters' activities levels in tissues homogenates across the groups of animals are presented as bar charts- labelled as figures- with variations of statistical significance emphasised $\left(^{*}\right)$ for attention. Aberrations are associated with regimen variations in legends and notes. Memory- short and long term- and anxiety were the neurobehavioural attributes being considered. Variations as observed were associated with both duration of exposure as well as the period and longevity of exposure. The results of these observations are presented using bar charts with statistical significance indicated $\left({ }^{*}\right)$. Charts are labelled as figures with suitable legends.

Results were presented on the basis of the groups and treatment as follows:

A: Control group animals 
B: Group B animals that were exposed to caffeine during pregancy and sacficed at birth

C: Group $\mathrm{C}$ animals that were exposed to caffeine during pregancy and sacficed at birth

D: Group D animals that were exposed to caffeine during pregancy and sacficed at birth

$\mathrm{B}^{\mathrm{C}+}$ : Group $\mathrm{B}$ animals that were administered low-dose pre- and postnatal caffeine

$\mathrm{B}^{\mathrm{C}-}$ : Group $\mathrm{B}$ animals that were administered only low-dose prenatal caffeine

$\mathrm{C}^{\mathrm{C}+}$ : Group $\mathrm{C}$ animals that were administered medium-dose pre- and postnatal caffeine

$\mathrm{C}^{\mathrm{C}-}$ : Group $\mathrm{C}$ animals that were administered only medium -dose prenatal caffeine

$D^{C+}$ : Group D animals that were administered high-dose pre- and postnatal caffeine

$D^{C-}$ : Group $D$ animals that were administered only high-dose prenatal caffeine.

Animals Groups that were administered caffeine made much less Primary Error Pokes (PEP) relative to the Control Group A (Fig. 1). In each group, there are variations in the number of PEP between the animal groups administered caffeine $(\mathrm{C}+)$ continuously to caffeine and the groups that did not receive postnatal caffeine administrations (C-). Caffeine ingestion affected the mice short term memory and only the lowest dose of caffeine at the prenatal and postnatal stages showed evidence of positive effects on memory. All the animal groups that were administered caffeine- prenatal and postnatal, had less Total Error Pokes (TEP) than the controls (Group A). There were no significant variations in the TEP on the basis of pre-natal and post-natal regimens of treatment as well as the dosage of caffeine administered across the groups. Based on the number of error pokes as a parameter for short term momory quality, the Group B animals showed improvement, albeit not statistically significant, relative to the other groups.

Primary Latency $(\mathrm{PL})$ as a memory attribute was lowest in the Group B animals with the Group $\mathrm{B}^{-}$mean value being lower than the Group $\mathrm{B}^{+}$. Other Groups' PL values were not significantly different especially relative to the control. Low dose caffeine ingestion in the Group $B$ had positive effects on memory. The average Total Latency ( $T L$ ) values vary across the experimental animal groups. The Group $B$ had the least values of TL. This is a positive result that showed that caffeine ingestion improved short term memory in the Group irrespective of the stage of exposure.

Experimental animal groups also exhibited variations in the mean numbers of the Primary Error Pokes (PEP) (Fig. 2). Animals that were administered caffeine until puberty (pre- and postnatal exposure), had reduced number of PEP relative to the controls (Group A) and the groups that had only prenatal expsoure. Total Error Pokes (TEP) varied across the groups, especially relative to the control. The Groups $\mathrm{B}^{\mathrm{C}+}$ and $\mathrm{C}^{\mathrm{C}+}$ had the least number of PEP values. Primary Latency varied across the groups of experimental animals. The animal groups that were administered caffeine in the pre- and postnatal (+ Caffeine) stages had lower PL relative to the groups that were only administered caffeine at the prenatal stage (- Caffeine). 
Also, these groups had higher PL relative to the control. Generally, animals (except $\mathrm{B}^{\mathrm{C}+}$ ) that were administered caffeine- either during the pre or postnatal stages, had higher TL relative to the control. TL was lower in the groups that were administered caffeine during the both the pre- and the postnatal stages (+ Caffeine) relative to the ones that were administered caffeine only in the prenatal stages (- caffeine).

Relative to the control (Group A) animals, pre- and postnatal-treated animals (Groups $\mathrm{B}^{\mathrm{C}+}$ and $\mathrm{C}^{\mathrm{C}+}$ ) had lower meam values of Time Spent in Open Arm (TSOA); their TSOA values are also lower than the TSOA values for the counterpart groups that only recived prenatal caffeine treatments (Groups $\mathrm{B}^{\mathrm{C}-}$ and $\mathrm{C}^{\mathrm{C}}$ ) (Fig. 3). Animals exhibited varying anxiety levels, but caffeine ingestion did not significnalty affect

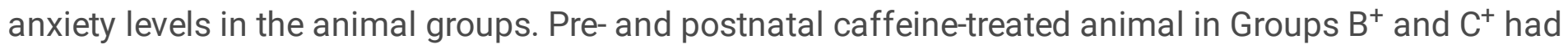
higher Time Spent in Close Arm (TSCA) when compared to their counterparts that were only administred caffeine in the prenatal stages (Groups $\mathrm{B}^{-}$and $\mathrm{C}^{-}$). The same Groups $\mathrm{B}^{+}$and $\mathrm{C}^{+}$had higher TSCA than the Control Group A TSCA value. These results showed that Animals exhibited varations in anxiety levels but caffeine ingestion did not significnalty affect anxiety levels in the animal groups.

Acetylcholine neurotransmitter activities in the brain tissues varied across the animal groups. Group B animals had higher levels; the Group $\mathrm{B}^{\mathrm{C}+}$ value was higher than he Group $\mathrm{B}^{\mathrm{C}-}$ values (Fig. 4). Continuos postnatal caffeine administration at the lower dose increased the level of the acetylcholine neurotransmitter significanlty. Serotonin activities also varied significantly between the control (Group A) and all the treated groups. There were no significant variations in serotonin levels between prenanal and perinatal caffeine-treated animals of the same main groups. Caffeine ingestion generally increased the levels of the serotonin neurotransmitter in the brains of the treated animals relative to the control. Group $B$ animas had the highest level of GABA activities in their brains. The levels were reduced in Group $C$ relative to both Control Group A animals as well as the Group B animals. Caffeine ingestion altered the levels of GABA neurotranmitters in the animals' brains across the experimental groups. However, there were no significant differences between the GABA levels in the brains of subgroups i.e. whether caffeine was only administered during the prenatal stage or during both the pre- and the postnatal stages.

\section{Discussion}

It is important to emphasise that the current investigation presents a functional and behavioural perspective into the effects of caffeine consumption on brain development, using the mice (Mus musculus) as a suitable model. There have been arguments in favour and against caffeine consumption in pregnancy as some reports have reported benefits (Juárez-Méndez et al. 2006; Connolly and Kingsbury 2010) and others, deleterious influences (Fuller et al. 1982; Desfrere et al. 2007). The regimen, timing and perspective limitations have however played major roles in interpreting observations in most existing reports. It is also crucial to state that the Group D animals did not survive till the end of the Phase II of the experiment period of 35 postnatal days. The animals died about the Day 12 of postnatal life. This incidence strongly suggests that this dosage was grossly deleterious to the animals and even the consequences of prenatal exposure resulted in death about the same time that the animals of the same

Page $11 / 33$ 
group that continued with the postnatal treatment died. In other words, the effects of the very high dosage of caffeine exposure in pregnancy resulted in death during the early days of postnatal life.

Caffeine had measurable effects on certain behavioural paramaeters (Fig. 1). Caffeine improved Barnes maze-tested short-term memory by reducing primary error pokes. Caffeine influenced the number of primary error pokes (PEP) in the treated groups generally relative to the control (Group A) significantly. Hence, prenatal and postnatal (chronic or habitual) caffeine administration affected cognition and shortterm memory. Treated animals general had lower values of primary error pokes (PEP) during the shortterm memory trials. The treated animals in Group $\mathrm{C}$ had the least number of PEP. Many investigations had considered short-term caffeine effects on learning, cognition and memory. Not many had modelled the regimen to align with various patterns in caffeine consumption as considered in this investigation. The effect of caffeine exposure on the postnatal life is also rarely studied in models. This investigation provides insights into these scenarios.

Obviously, all treated animal groups- both the ones that only had prenatal caffeine exposure and those that had both pre- and postnatal exposure had low PEP values relative to the control. These observations would suggest that caffeine affected memory in all the groups relative to the control. Low PEP values indicated that the animals in this investigation had greater accuracy in recognising the target escape from the Barnes maze. This indicated that they had improved short-term memory by making much less mistakes in recognising the escape hole (Barnes 1979; Sunyer et al. 2007). Those that had caffeine administered to the mothers only during pregnancy in had slightly lower PEP values when compared with their counterparts in the same group that had caffeine administered to their mothers and then had caffeine administered to them as well until puberty. Whereas in group in which animals had boh pre-and postnatal caffeine treatment had much less PEP value that their counterparts. What is consistent with these observations is that caffeine administration could influence PEP which is a measure of memory retrieval accuracy either when administered to the mothers of offspring in pregnancy only or when this treatment to the offspring themselves after parturition.

The above further suggests that caffeine is effective at certain doses by virtue of its mechanism on the brain to influence memory by improving accuracy of decisions and activities based on experience and training. In the context of accuracy, caffeine had affected memory positively at lower doses. Costa et al. (2008) reported that short-term caffeine administration improved short term memory in rats. Cupo (2012) reported similarly for the short term memory but stated that chronic caffeine consumption impairs long term memory, contrary to the current findings. Borota et al. (2014) stated that caffeine administration in humans would enhance memory consolidation. Notably, the regimen in the last two investigation did not model the human habitual method of caffeine consumption- administration was done for four weeks through injection and tailored towards task performances rather than routine habitual uses. This would illustrate the diversities that are associated with results due to methods of investigation. It is alo worthy of mention that caffeine effects could also be modulated by other factors including sleep deprivation (Pauldurai 2014). 
Caffeine pre- and postnatal exposure produced positive effects on short term memory and cognition by reducing the total error pokes (TEP). Caffeine produced lowered TEP in all treated groups and sub-groups, with the exception of the extremly high dose that caused postnatal death. This indicated that caffeine use, whether during pregnancy alone or cntuinually afterwards, have the potential to influence mental attributes of mental accuracy and cognition and memory, resulting in reduced recog-nition rooers as tested in thjis study. Thus caffeine had sustained effects on memory and cognition in the experimental animals. This is still in line with the aforementioned report of Borota et al. (2014).

Moderate caffeine exposure produced positive effects on short term memory and cognition by reducing the primary latency $(\mathrm{PL})$ (Fig. 1). Primary latency is a good parameter for evaluating cognitive performance; since it is a major parameter for assessing spatial learning and memory (Barnes 1979; Harrison et al. 2009). Caffeine has been reported to have influence on cognitive performance either in humans (Johnson-Kozlow, et al. 2002; Kelly et al. 2008; Beaven and Ekström 2013) or models (DombovyJohnson, 2012). However, while most reports have only investigated acute or prolonged non-habitual caffeine consumption and its effects; the current investigation considered the effects during pregnancy and its postnatal implications in conditions of continuity or otherwise. Primary latency (PL) variations showed the time taken to locate the escape hole (Barnes 1979; Sunyer et al. 2007) and it is a marker of cognition and memory quality in the animal groups. The Group $B$ animals exhibited significant reduction in PL relative to the control (Group A); this showed improved agility and memory. There are however only slight differences between the PL values for the Group C and the control, Group A. This observation suggested the possibility of a curve relationship between this particular type of effects and the PL component of the short-term memory as observed in this investigation. This observation would also point to a possibility of a moderate optimal dose for effective $P L$ after which there was decline in effectiveness by virtue of the increase in $\mathrm{PL}$ values. This type of phenomenon has been demonstrated by the interactions of several agents with body systems and functional mechanisms. Interestingly, the Groups $\mathrm{C}^{-}$animals whose mothers were administered caffeine during pregnancy (but without postnatal exposure) had the relatively highest PL value in and similar fashion to the PEP and TEP values. It is quite possible that caffeine at quite high dose could be losing the positive effects attributed to its actions. A number of reports had stated that caffeine at relatively high doses could have negative effects on attributes of mental functions such as cognition, learning and memory (Mednick et al. 2008; Jones and Fernyhough 2009).

Moderate pre- and postnatal caffeine use produced positive effects on short term memory by reducing total latency (TL) (Fig. 1). The Total Latency (TL) pattern followed a trend similar to PL across the animal groups. The Group B animals had the least value and within this Group, the subgroup, Group $\mathrm{B}^{\mathrm{C}-}$ has the lower value of TL. This is consistent with the PL and a number of other memory attributes previously considered. Positive effects of caffeine relative to latency is being observed in this Group B. The animals in this group needed shorter time to deploy the memory from previous experience or learning in finding the escape hole. This characteristic is quite positive for memory. Again, it would appear that the dosage employed at this level was most appropriate to elicit a positive effect on TL as an attribute of memory. 
Contrary to Group B, the Group C animals had TL values close to the TL values in the control (Group A). This would indicate that caffeine administration in this group did not produce significant lowering nor increase in the TL values; hence, the TL attribute of memory was neither significantly improved nor worsened. This reinforces the possibility of a curve-phenomenon for the dosage-effect relationship between TL or memory attributes and the dosage of caffeine consumed. Therefore, caffeine only affected latency positively at the lower or moderate dosage and this is in line with several previous reports (Mednick et al. 2008; Jones and Fernyhough 2009).

While caffeine administration before birth alone (Group B) as opposed to caffeine administration before birth (to mother) and after (continuously to the offspring) (Group $\mathrm{B}^{\mathrm{c}+}$ ) produced a relatively lower TL value, effect is reverse in the case of Group C. In other words, caffeine consumption withdrawal after birth at the lower dosage in Group B produced slightly lower TL signifying better TL value as a memory attribute; however, the withdrawal in Group $C$ resulted in slight increase of the TL value signifying a slightly poorer TL attribute of memory relative to Group $\mathrm{C}^{\mathrm{C}+}$ and the control (Group A). Thus, the effects of caffeine on TL as a vital attribute of the short-term memory as observed here is dose dependent as much as it is influenced by the periods of administration- whether prenatal or postnatal stages alone or at both periods of life. This observation points to the need to carefully evaluate the relationship between potency and dosage even within the safe-dose range values even for the acclaimed benefits of caffeine since it appears that high dosage, though not necessarily lethal or deleterious might still affect vital mental attributes negatively.

Furthermore, there is evidence that the mothers' caffeine ingestion in pregnancy affected latency till postnatal adolescence or puberty. This agrees with a number of reports on the possibilities of sustaining the effects that caffeine ingestion during pregnancy might have on the offspring till adult postnatal life stage (Juárez-Méndez et al. 2006; Connolly and Kingsbury; Fuller et al. 1986; Desfrere et al. 2007). Negative effects of high caffeine dosage are also reported to be associated with adult neurogenesis (Wentz and Magavi (2009). Though Atik et al. (2014) reported that high caffeine consumption during pregnancy is safe based on structural examination of the ovine brain, it should be noted that in their instance, administration was only during the latter stage of prenatal life (0.7-0.8 of term; approximately 27-34 wk of gestation in humans). This is contrary to most real life situation where caffeine users might consume caffeine regularly irrespective of the stage of pregnancy. The real life situation is therefore more closely related to the current research design.

Continuous pre- and postnatal caffeine exposure produced positive effects on long term memory by relatively reducing the primary error pokes (PEP). The PEP values were lowered in the Groups $\mathrm{B}^{\mathrm{C}+}$ and $\mathrm{C}^{\mathrm{C}+}$ (which were administered caffeine at both pre- and postnatal stages) relative to the control (Group $A$ ) and their counterpart Groups $\mathrm{B}^{\mathrm{C}-}$ and $\mathrm{C}^{\mathrm{C}-}$ (that were administered caffeine only at the prenatal stage). The positive influence of caffeine is observably more effective in Group $\mathrm{B}^{\mathrm{C}-}$ that was administered a lower dosage of caffeine than the Group $\mathrm{C}^{\mathrm{C}+}$ that was administered the higher dosage of caffeine. This would still support the observation that potency relative to PEP attribute of memory is achieved at the moderate 
or lower dosage employed. While caffeine withdrawal at the post natal stage in Group B (Group $\mathrm{B}^{\mathrm{C}-}$ ) produced higher PEP average value, both relative to the control (Group A) and the counterpart Group $\mathrm{B}^{\mathrm{C}+}$; PEP in Group $\mathrm{C}^{\mathrm{C}-}$ was only slightly higher than it was in its counterpart Group $\mathrm{C}^{\mathrm{C}+}$ but lower than it was in the control (Group A).

Effects of moderate caffeine ingestion during pregnancy improved spatial learning and memory accuracy when postnatal consumption was continued; these two parameters are typically measured by the Barnes maze test (Harrison et al. 2009; Mouzon and Chaytow 2012). Meanwhile Silva et al. (2013) had reported on caffeine effects on hippocampus that persisted in the mice till later postnatal life. The mice were reportedly less exploratory and unwilling to be adventurous with learning. GABA neurons were reported to have failed to migrate properly. Also, caffeine adenosine antagonist action was reported as the primary mechanism involved (Silva et al. 2013). Though the dosage of caffeine used was above what is considered moderate in the context of the current investigation; it remains a pointer to the possibility of the persistence of established caffeine effects in pregnancy. Understandably, some of such effects could be positive and beneficial to vital mental functions.

When caffeine consumption was stopped after birth, after having exposed the offspring to it in pregnancy through their mothers; LTM-PEP values increased both relative to the values in non-caffeine consuming mothers and caffeine consuming mothers' offspring. Thus, only continuous caffeine consumption could achieve improved memory via the lowering of the PEP values. While this again would appear to be a positive attribute of caffeine moderate use both during pregnancy and after birth on the offspring, it is also important to note that this could mean permanent functional adjustments in mental attributes. These changes might have occurred through chemical and structural adjustments that have influenced relevant mental attributes. Hence caffeine effect is influenced both stage of development at which the brain is exposed as much as the dosage employed (Lopez et al. 1989; Nehlig et al. 1992; Guillet and Dunham 1995).

The total error pokes (TEP) values pattern across the animal groups was similar to that of the PEP (Fig. 1). The continuous administration of caffeine from the prenatal stage (to the mothers) to the postnatal stage (to the offspring) reduced the values of TEP for the animals. This would suggest that the TEP attribute of memory was effectively reduced when the substance was continually administered, and the advantage might be lost upon stoppage of administration to the offspring after birth. Also, it would appear that the error pokes were most effectively reduced when the dosage was low or moderate during the pregnancy and postnatal life. A consistent fact is that caffeine's effect during pregnancy could still be observed till puberty in spatial learning and memory accuracy (Holloway 1982; Hughes and Beveridge, 1990). While it is positive for the continually treated groups; it is rather negative for the groups that were only exposed during pregnancy alone in terms of the TEP as a parameter for evaluating spatial learning and memory (Sunyer et al. 2007). Only the lower or moderate dosage produced observable positive effect on TEP. 
Moderate continuous pre- and postnatal caffeine exposure produced positive effects on long term memory by relatively reducing the primary latency $(\mathrm{PL})$, but postnatal withdrwal was relatively counterproductive. Caffeine evidently affected PL; its chronic pre- and postnatal administration was positive on spatial learning and memory performance (Brice and Smith 2002). The primary latency (PL) attribute of the memory was influenced by caffeine administration relative to the control (Group A). There were also variations within groups- between the animal groups administered only during pregnancy and those administered caffeine at both the prenatal and postnatal stages. The administration of caffeine at both pre- and postnatal stages of development produced lower PL values than when it was only administered for the animals' mothers in pregnancy and discontinued after birth. Again, the effective dosage in terms of lowering the PL values is when the dosage was low or moderate and the administration was first to the animals' mothers in pregnancy and afterwards to the offspring themselves until puberty (Group $\mathrm{B}^{\mathrm{C}+}$ ). At the higher dosage (Group $\mathrm{C}^{\mathrm{C}+}$ ), the $\mathrm{PL}$ value was lower relative to what it was when administration was stopped right from birth (Group $\mathrm{C}^{\mathrm{C}-}$ ). The lowering of the $\mathrm{PL}$ values between these groups however was still not effective relative to the control (Group A). The persistence of caffeine effects on animal behaviour had been reported, previoulsy (Holloway 1982; Gullberg et al. 1986; Nakamoto et al 1991).

In a similar fashion to its effects on PL, low or moderate continuous pre- and postnatal caffeine exposure produced positive effects on long term memory by relatively reducing the total latency (TL). In this instance, postnatal withdrawal was relatively counterproductive. The total latency (TL) attribute of the long-term memory showed observable relationships between caffeine dosage and the period of administration between the groups and the control animals. Caffeine administration influenced TL positively and most effectively when administered at moderated dosage to the mothers before birth and then to the offspring until puberty (Group $\mathrm{B}^{\mathrm{C}+}$ ). This advantage however was lost (in the counterpart Group $\mathrm{B}^{\mathrm{C}-}$ ) when caffeine administration was only done through the mothers during pregnancy. $\mathrm{TL}$ values were higher (relative to the Group $A$ ) when the higher caffeine dosage was employed (Group $\mathrm{C}^{\mathrm{C}+}$ and Group $\mathrm{C}^{\mathrm{C}}$ ). There was no significant difference in the resultant effects on TL when caffeine administration was stopped at birth. This observation is largely consistent with the possibility of a curve phenomenon relative to the influence of caffeine administration vital attributes of memory. In line with this, the specifically positive effects dosage was the lower dosage employed in this investigation and when caffeine was both administered through the mothers in pregnancy and when this was continued until puberty. Obviously, the stoppage of caffeine administration after birth greatly and significantly increased the value of TL and this is interpreted as a negative effect since it would imply that latency in achieving escape through a learned procedure was increased.

Caffeine reportedly improved performance on cognitive tasks (Smith et al. 1994; Hogervorst et al. 1999; Lieberman et al. 2002; Brice and Smith 2002; Howard and Marczinski 2010); and benefited the elderly the more (Jarvis 1993), with women appearing relatively favoured the more (Johnson-Kozlow et al. 2002). Evidently, caffeine consumption would require moderation because excessive doses have been reported to be detrimental to working memory (Foreman et al. 1989). This is attributable to a number of 
mechanisms- direct antagonistic effects on adenosine receptors (AR1 and AR2A), influence on neurotransmitters and glucose metabolism among others.

When exploratory and anxiety-related parameters were assayed using the elevated plus maze, caffeine increased animals' activeness and exploratory behaviour by relatively increasing the frequencies of openclose arms movements (Fig. 3). The frequency and pattern of entries and exits between the close arm and the open arm of the elevated plus maze neurobehavioral tool for anxiety provided useful insight into anxiety related behavioural attributes of the experimental animals. The close arm entry (CAE) is used as a direct indication of anxiety (Walf and Frye 2007; Komada et al. 2008) as well as an indirect indication of animal activeness. The control (Group A) animals had the lowest mean CAE value. This could simply suggest lower levels of activities rate or reduced activeness relative to the other animal groups administered caffeine of various dosages at various stages. While it could give a direct picture of the pattern of activeness, it would also suggest anxiety, although until it is measured against the rate at which the animals exit the close arm as well as the time spent in the open and the close arms of the maze. Therefore, it is logical to deduce that the general administration of caffeine improved animals' activeness generally, including those who had received caffeine only during intrauterine development through their mothers. There is the possibility of increased anxiety level as well; anxiety has strongly been associated with caffeine consumption (Goldstein et al. 1969; Alsene et al. 2003).

Furthermore, the receptors (AR1 and AR2A) that caffeine primarily interact with are strongly linked with anxiety (Ledent et al.1997; Johansson et al. 2001). Animals that received caffeine continuously after birth (Groups $\mathrm{B}^{\mathrm{C}+}$ and $\mathrm{C}^{\mathrm{C}+}$ ) had higher $\mathrm{CAE}$ values than their counterparts that only received similar treatments during intrauterine life (Groups $\mathrm{B}^{\mathrm{C}-}$ and $\mathrm{C}^{\mathrm{C}-}$ ). Hence, caffeine treatment right from pregnancy influenced activeness until puberty; so also the continual administration of caffeine through pregnancy and afterwards. The latter however had greater effects on the CAE attribute of anxiety. This in line with many previous investigations on caffeine anxiogenic roles (Childs et al. 2008; Rogers et al. 2010).

The close arm entry (CAE) measurements provided information on both activeness and explorative abilities of the animals especially in a manner that complements the OAE values. The animal groups that were administered caffeine (whether prenatal only or pre- and postnatal) all had average Open Arm Entry $(\mathrm{OAE})$ values higher than the control (Group $A$ ) indicating increased inter-arms motor activities and movements relative to the control (Group A). Interestingly, this is quite consistent with the results of the CAE particularly relative to activeness and explorative tendencies and abilities. Previous reports stated that caffeine increased alertness, induced locomotor activation and could cause hyperactivity (Zahniser et al. 2000). This has been attributed largely to its interactions with adenosine receptors, dopamine receptors and GABA which are typically implicated in behavioural hyperactivity. While it could have suggested increased anxiety; it is also logical to state that increased movements in- and out of the close arms might not exclusively represent increased anxiety, as this would only be so if they stayed in the close arm relatively longer than they stayed in the open arm (this is measured by the time spent in closed arm versus the time spent in the open arm that would be considered after this part). Rather, it is quite more rational and logical to deduce that the animals were quite exploratory and active. This could be a 
positive behavioural attribute; and as such, attributes had been associated with improved learning or interest in learning even in humans.

There is no significant difference in the OAE values for the Group B (Group $\mathrm{B}^{\mathrm{C}+}$ and Group $\mathrm{B}^{\mathrm{C}-}$ ) animals suggesting that such effects could have been established during the intrauterine development of the brain. In line with this, it is possible that this becomes a lasting mental attribute for the animals, having persisted it until puberty. It could also mean that factors that are responsible for this attribute were most susceptible for caffeine actions influence during the intrauterine periods of development with no significant influence taking place during postnatal life treatment. At the higher dosage employed; there is a slight lowering in the OAE between the continually treated Group $\mathrm{C}^{\mathrm{C}+}$ and the counterpart Group $\mathrm{C}^{\mathrm{C}-}$ implying a slight lowering of the level of movement activities and exploratory tendencies in this group relative to this counterpart. Generally, moderate dose caffeine administration improved activeness and exploratory tendencies. Caffeine neonatal administration has been reported to cause sustained increase in the adenosine receptor- $A_{1}$ density in adult rats (Montandon et al. 2006) and this could be a major contributory factor to the observed changes.

Pre- and postnatal (continuous) caffeine exposure produced anxiety tendencies by realtively increasing the TSCA and reducing the TSOA. Relative increase in time spent in open arm (TSOA) is considered a positive neurobehavioral attribute as it indicates less anxiety (Walf and Frye 2007; Komada et al. 2008). The prenatal treated animal groups $\left(\mathrm{B}^{\mathrm{C}-}\right.$ and $\left.\mathrm{C}^{\mathrm{C}}\right)$ had quite relatively high TSOA. Not only was their TSOA higher than the control (Group A), they were also greater than their counterparts' TSOA values. This could be logically explained to reflect an influence of caffeine on this attribute of behaviour. Caffeine consumption during pregnancy (by the mothers) has produced effects on the brains of the offspring. Furthermore, these effects would have taken place during the intrauterine development but with lasting effects on behaviour. The values of TSOA in the counterpart groups that were administered caffeine preand postnatal did not show significant increase or depreciation in the TSOA values. This is an evidence in support of the fact that significant effects were majorly produced by virtue of caffeine effects on brain intrauterine development. Continual consumption of caffeine during postnatal stage rather than enhance TSOA values appear to have nullified the influence it produced during the intrauterine stage of development.

Pre- and postnatal caffeine-treated animal Groups $\mathrm{B}^{\mathrm{C}+}$ and $\mathrm{C}^{\mathrm{C}+}$ had higher Time Spent in Close Arm (TSCA) than their counterparts in the prenatal-treated Groups $\mathrm{B}^{\mathrm{C}-}$ and $\mathrm{C}^{\mathrm{C}-}$. This implied that animals that were administered caffeine throughout pregnancy till birth and then up to puberty had raised or increased anxiety tendencies relative to their counterparts that only received caffeine treatment through their mother in pregnancy. Another fact that could be deduced from this is that these effects might have been continuous based on the caffeine treatment regimen and not necessarily permanently established in pregnancy. Interestingly, the prenatal treated groups (Groups $\mathrm{B}^{\mathrm{C}-}$ and $\mathrm{C}^{\mathrm{C}-}$ ) had lower TSCA values relative to the control (Group A) as well. This could only be logically explained as to mean that caffeine consumption by mothers in pregnancy alone could normalise anxiety tendencies in the offspring that

Page 18/33 
would not consume caffeine on their own during postnatal life. Notably again, a moderate dosage of consumption by the mothers in pregnancy caused a significant reduction in the TSCA value (Group $\mathrm{B}^{\mathrm{C}-}$ ), suggesting the roles and influence of dosage moderation on the underlying mechanism. While the current analysis would be based on a brain in its state of relalive normal health; it will be important to investigate these effects in various major neuerorlgocal aberration conexts. For example, Zappettini et al., [2019] had stated in their report that intrauterine exposure to caffeine could be a risk-factor for early onset of Alzheimer's disease-like pathology. On the other hand, Alsayed et al., [2017] had reported that perinatal caffeine exposure $(60 \mathrm{mg} / \mathrm{kg})$ affected learning and memory significantly. However, they reported no alternations in anxiety and social behavior.

While Nehlig et al. (1992) stated that caffeine consumption affected learning memory and performance, the current investigation explains further how lasting such influence could be. Since these mental attributes are associated with adenosine receptors; it is also in line with the report of Shi et al. (1993) and Zielke and Zielke (1987) that caffeine chronic consumption caused up-regulation of adenosine receptorsAR1; which reportedly could be persistent. However, the report of Lorenzo et al. (2010) suggested that the time of caffeine exposure influences adenosine receptors response to caffeine differently- neonates' exposure reportedly decreased adenosine receptor- AR1 response while AR2A was unaffected. Upregulation of AR1 might have positive or therapeutic implications- it has been associated with repair of ischemic damage in gerbil hippocampus (Rudolphi et al. 1989). Other methods of evaluation had confirmed caffeine-induced behavioural changes (Hughes and Beveridge 1990).

It is also important to disucss the effects of caffeine exposure on selected neurotransmitters. Caffeine exposure altered acetylcholine (ach) activities levels in the brain with the moderate dosage producing suatained optimal elevations. Acetylcholine neurotransmitter activities levels in the brain tissues varied across the animal groups. This is attributable to caffeine, in line with some previous investigations that reported caffeine roles in modulation of neurotransmitters activities including acetylcholine (Acquas et al. 2002; Cauli and Morelli 2005; Ferré 2010; Acquas et al. 2010; Lopez-Cruz et al. 2013). Group B animals generally had the highest levels; the Group $\mathrm{B}^{\mathrm{C}+}$ value was higher than Group $\mathrm{B}^{\mathrm{C}-}$ value. This neurotransmitter was no doubt influenced by the dosage of administration as well as the timing of the caffeine administration. The level was highest when caffeine was administered at the lower dosage in Group $\mathrm{B}^{\mathrm{C}+}$ right from pregnancy (to the mothers) and continuously till puberty. Interestingly, the counterpart group (Group $\mathrm{B}^{\mathrm{C}-}$ ) that were administered caffeine only during pregnancy has the next highest level of ACh neurotransmitter in their brains. This implied that the effects were more influenced by the time of administration and dosage because the high level of $A C h$ in the Group $\mathrm{B}^{\mathrm{C}-}$ was relatively sustained till adult despite the fact that they only received caffeine through their mothers during pregnancy. Another fact deducible from this observation is that the lower dose was more effective at producing an elevated level of this neurotransmitter even more than the higher dose employed in Group C. To this end, the molecular mechanism responsible for this elevation would have been established during intrauterine development for there to be sustenance of such effects beyond prenatal period. 
The higher dosage of caffeine as employed in the Group C produced lower Ach levels relative to the control, Group A and the Group B animals. Acetylcholine modification has been reported to influence memory- it was reported to selectively suppress intrinsic but not afferent fiber synaptic transmission in the visual cortex and this effect was associated with preventing recall of previously learned memories from interfering with the learning of new memories (Hasselmo and Bower 1993). Furthermore, acetylcholine effects in the piriform cortex were specifically reported to include suppression of neuronal adaptation, suppression of synaptic transmission in the intrinsic fibers layer, and activity-dependent increase in synaptic strength. These were summed up to enhance learning and recall performance of the cortical network; thus emphasising its roles in learning and memory (Barkai and Hasselmo 1997).

When considered relative to Group A, caffeine at the higher dosage produced effects that reduced ACh levels in both subgroups. Again, the relative closeness of the neurotransmitter levels in both groups points to the insignificant effects that caffeine administration might have on the established levels of this neurotransmitter when administered during postnatal life. The high dosage on the other hand could have been beyond the optimal dosage to effect ACh elevation; thus a reduction resulted. Altogether, caffeine influenced the brain chemistry relative to this neurotransmitter in manners that are persistent till puberty. To this end, there is the possibility that specific functions that are associated with this neurotransmitter could be influenced right from pregnancy and sustained for a long period beyond parturition.

A major role of acetylcholine that is related to tested parameter in the current investigation is learning and memory- of which long term potentiation (LTP) is a major determinant (Persad 2011). LTP is influenced by acetylcholine (Myhrer 2003) in conjunction with dopamine, serotonin and epinephrine. Acetylcholine is basically involved in cognitive functions by interacting with dopamine while it influences cognitive behaviour with serotonin (Persad 2011). Also, caffeine can consistently and chronically influence the effects of acetylcholine (Acquas et al. 2002)

The GABA ( $y$-Aminobutyric Acid) neurotransmitter levels varied between the animal groups with the Group $B$ animals having the highest levels of this nuerotransmitter in their brains. Both subgroups of animals had similar levels of the enzyme. This would imply that the continuous postnatal administration of caffeine in the Group $\mathrm{B}^{\mathrm{C}+}$ did not produce any substantial difference between this group and the counterpart Group $\mathrm{B}^{\mathrm{C}-}$ that received the same dosage but only through the treatment given their mothers in pregnancy. Again, it is logical to deduce that the effect of caffeine that were observed on the GABA neurotransmitter in this study had a prenatally established cause, possibly through an influence on the underlying molecular mechanisms. This dosage as well was the most effective for increasing the level of this neurotransmitter in the current study.

The animal groups that were administered the higher dosage of caffeine had much lower GABA activities levels in their brains than their counterparts administered with the lower dosage. They also had lower levels of GABA activities when compared with the control. Caffeine had previously been reported to reduce GABA receptor interaction sites (Roca et al. 1988) or alter the density (Shi et al. 1993). Since these levels were quite close in both subgroups, prenatal administration did not cause any substantial increase 
relative to the levels produced by the intrauterine treatment at this particular dosage. Rather, there was a slight reduction in the neurotransmitter's activities level when caffeine was continuously administered during postnatal stage of life. There was therefore no increase to this neurotransmitter as a result of caffeine administration during postnatal life relative to their counterparts that were only treated in pregnancy. High caffeine dosage would therefore rather reduce the level of GABA. Again, there is the possibility of an optimally efficient dosage of caffeine with respect to the elevation of GABA around the lower dosage employed and which the dosage employed in Group $\mathrm{C}$ was beyond.

Pre and postnatal caffeine exposure produced sustained alterations in serotonin neurotransmitter levels with the optimal levels being assoaciated with the moderate dosage. The Serotonin (SER) neurotransmitter's activity in the animals' brain was highest in the Group B. Both subgroups of animals (Group $\mathrm{B}^{\mathrm{C}+}$ and Group $\left(\mathrm{B}^{\mathrm{C}-}\right.$ ) had quite relatively high levels of serotonin in their brain tissues. There was no substantial difference between the levels of this neurotransmitter in these two animal subgroups. Notably, only one of these subgroups (Group $\mathrm{B}^{\mathrm{C}+}$ ) received caffeine till puberty, the other only received through their mothers during the prenatal stage; yet both subgroups had serotonin levels that were almost equal in the brain tissue. This strongly suggested that the determinants of such neurochemical changes were established during intrauterine development. This would further imply that caffeine could influence brain chemistry and serotonin levels and functions during pregnancy, and this could be sustained as long as puberty.

Serotonin level, rather than increase with increase in dosage (in Group C) had a reduction in activities levels. This group of animals did not just have lowered serotonin levels relative to the Group B animals that were administered the lower dosage of caffeine, they also had it lower than that of the control (Group A). There was substantial difference between the levels of serotonin in both subgroups (whether caffeine was administered during prenatal stage alone or continuously till puberty. his reinforces the argument that caffeine would have influenced the factors and molecular mechanisms that were responsible for the changes in serotonin levels before birth and such effects might persist until postnatal life. Again, caffeine reduced serotonin activities levels at the relatively high dosage showing that increase in its dosage did not always continuously produce increase in serotonin level, this curve-phenomenon of dose-effect response has been consistently suspected from caffeine effects for a number of vital neurotransmitters in this investigation.

\section{Summary And Conclusion}

These findings are in alignment with certain previous works including that of Park (2016) which had reported that ealry life caffeine exposure could have persisitent effects on normative neuronal function. Also, caffine intrauterine exposure reportedly affected GABA neurons, brain rhythms and memory (Fazeli et al. 2017). The report of park (2016) had also shown that perinatal caffeine exposure affected synaptic efficacy in the hippocampus of freely moving adult rats and this might also have significnat functional consequences on memory and/or cognition. These findings are also pointers to the importance of the recommendations of the American College of Obstetricians and Gynecologists (2010) on moderate 
caffeine consumption during pregnancy and why this might be continually critically reviewed in line with further emerging evidences.

From the current investigation, caffeine exposure in pregancy had persistent effects on brain functional attributes including neurotransmitters activities, memory and anxiety. Caffeine morderate dosage affected memory positively, especially when prenatal exposure was sustained during the postnatal stage but produced negative effects at the higher dosage including increased anxiety tendencies and death at the highest dose employed.

\section{Declarations}

\section{Data availability statement}

The article contains all essential data; additional research data and information will be made availlable upon reasonable request through the corresponding author.

\section{Disclosure of potential conflicts of interest}

All authors disclose no conflict of interest

\section{Compliance with ethical standards}

Authors declarare that all applicable international, national, and/or institutional guidelines for the care and use of animals were followed.

\section{Author's Contribution:}

Author OJO carried out laboratory experiments, Author AKA and SPD contributed to data curation and results analysis, Authors FOS, OSY, and OJA contributed to laboratory experimental activities and tissues processing, Author ATP contributed to resust analysis and drafting of the article, Author OS contributed to laboratory experimental activities and animal holding management, Author, OPO provided expert guidance and contributed to data curation, analysis, and presentation. All authors contributed significantly to the writing of the final manuscript and reviews.

\section{References}

ACOG Committee Opinion No. 462 (2010) Moderate caffeine consumption during pregnancy. American College of Obstetricians and Gynecologists. Obstet Gynecol. 116(2 Pt 1):467-468.

Acquas E, Tanda G, Di Chiara G (2002) Differential effects of caffeine on dopamine and acetylcholine transmission in brain areas of drug-naive and caffeine-pretreated rats. Neuropsychopharmacol 27:182193 
Acquas E, Vinci S, Ibba F, Spiga S, De Luca MA, Di Chiara G (2010) Role of dopamine D(1) receptors in caffeine-mediated ERK phosphorylation in the rat brain. Synapse 64: 341-349

Ådén U, Herlenius E, Tang L, Fredholm, BB (2000) Maternal Caffeine Intake Has Minor Effects on Adenosine Receptor Ontogeny in the Rat Brain. Pediatr Res 48:177-183

Alsayed A, Jamal M, Al Hoty N, Eqab S, Ahmadi N, Sameer M, Alathem A, Al Saqer M, Alsulami B and Kamal A (2017) Perinatal Administration of Caffeine in Mice Affects the Spatial Memory and Motor Coordination Later in Adult Life. J Brain Disord 1(1):4-11.

Alsene K, Deckert J, Sand P, de Wit H (2003) Association between A2a receptor gene polymorphisms and caffeine-induced anxiety. Neuropsychopharmacol 28(9):1694-702

Atik A, Cheong J, Harding R, Rees S, De Matteo R, and Tolcos M (2014) Impact of daily high-dose caffeine exposure on developing white matter of the immature ovine brain. Pediatr Res 76 (1): 54-63

Barkai, E. and Hasselmo, M. H. (1997). Acetylcholine and associative memory in the piriform cortex. Mol Neurobiol 15(1): 17-29

Barnes CA (1979) Memory deficits associated with senescence, a neurophysiological and behavioral study in the rat. J Comp Physiol Psychol 93:74-104

Beaven CM, Ekström J (2013) A Comparison of Blue Light and Caffeine Effects on Cognitive Function and Alertness in Humans. PLoS One 8(10): e76707. doi, 10.1371/journal.pone.0076707

Bernstein GA, Carroll ME, Thuras PD, Cosgrove KP, Roth ME (2002) Caffeine dependence in teenagers. Drug Alcohol Depend 66(1):1-6

Borota D, Murray E, Keceli G, Chang A, Watabe JM, Ly M, Toscano JP, Yassa MA (2014). Post-study caffeine administration enhances memory consolidation in humans. Nat Neurosci 17: 201-203

Brice CF, Smith AP (2002) Effects of caffeine on mood and performance, a study of realistic consumption. Psychopharmacol 164:188-192

Castellanos FX, Rapoport JL (2002) Effects of caffeine on development and behavior in infancy and childhood, a review of the published literature. Food Chem Toxicol 40 (9):1235-1242

Cauli O, Morelli M (2005) Caffeine and the dopaminergic system. Behav Pharmacol 16:63-77

Childs E, Hohoff C, Deckert J, Xu K, Badner J, and de Wit H (2008) Association between ADORA2A and DRD2 polymorphisms and caffeine-induced anxiety. Neuropsychopharmacology 33(12):791-800

Connolly S, Kingsbury TJ (2010) Caffeine modulates CREB-dependent gene expression in developing cortical neurons. Biochem Biophys Res Commun 397:152-156 
Costa MS, Botton PH, Mioranzza S, Souza DO, Porciuncula LO (2008) Caffeine prevents age-associated recognition memory decline and changes brain-derived neurotrophic factor and tirosine kinase receptor (TrkB) content in mice. Neurosci 153:1071-1078 oi, 10.1016/j.neuint.2008.06.006

Cupo RG (2012) The Effects of Caffeine on Spatial Learning and Memory. Master's Degree Thesis, Seton Hall University.

D’Amore A, Mazzucchelli A, Loizzo A (1995) Long-Term Changes Induced by Neonatal Handling in the Nociceptive Threshold and Body Weight in Mice. Physiol Behav 57 (6): 1195-1197

Daly JW (1993) Mechanism of action of caffeine in Caffeine, Coffee, and Health, ed Garattini S Raven Press, New York, pp 97-150.

Desfrere L, Olivier P, Schwendimann L, Verney C, Gressens P (2007) Transient inhibition of astrocytogenesis in developing mouse brain following postnatal caffeine exposure. Pediatr Res 62 (5): 604-609

Dombovy-Johnson M (2012) The Effects of Taurine and Caffeine Alone and in Combination on Locomotor Activity in the Rat. Colgate Acad Rev 7:10

Elisa (2015). Elisa Enzyme-linked ImmunosorbentAssay Kit for Gamma-Aminobutyric Acid (GABA). Houston. www.cloud-clone.us Accessed 25 May 2018.

Elkins RN, Rapoport JL, Zahn TP, Buchsbaum MS, Weingartner H, Kopin IJ, Langer D, Johnson C (1981) Acute effects of caffeine in normal prepubertal boys. Am J Psychiatry 138(2):178-183

Fawcett A (2012b) Guidelines for the Housing of Mice in Scientific Institutions, Animal Research Review Panel, NSW Department of Primary Industries, Animal Welfare Unit, West Pennant Hills; Recommendation 2.2.1, p. 40

Fawcett A (2012c) Guidelines for the Housing of Mice in Scientific Institutions, Animal Research Review Panel, NSW Department of Primary Industries, Animal Welfare Unit. West Pennant Hills, p. 40-111.

Fazeli W, Zappettini S, Marguet SL, Grendel J, Esclapez M, Bernard C, Isbrandt D (2017) Early-life exposure to caffeine affects the construction and activity of cortical networks in mice. Exp Neurol. 295:88-103

Ferré S (2010) Role of the central ascending neurotransmitter systems in the psychostimulant effects of caffeine. J Alzheimers Dis 20 (1):S35-S49.

Foreman N, Barraclough S, Moore C, Mehta A, Madon M (1989) High doses of caffeine impair performance of a numerical version of the Stroop task in men. Pharmacol Biochem Behav 32:399-403 
Frary CD, Johnson RK, Wang MQ (2005) Food sources and intakes of caffeine in the diets of persons in the United States. J Am Diet Assoc 105(1): 110-113

Fredholm BB, Bättig K, Holmén J, Nehlig A, Zvartau EE (1999) Actions of Caffeine in the Brain with Special Reference to Factors That Contribute to Its Widespread Use Pharmacol Rev 51:83-133

Friedman M (2007) Overview of antibacterial, antitoxin, antiviral, and antifungal activities of tea flavonoids and teas. Mol Nutr Food Res 51(1):116-134

Fuller GN, Divakaran P, Wiggins RC (1982) The effect of postnatal caffeine administration on brain myelination. Brain Res 249:189-191

Goldstein A, Kaizer S, Whitby $O$ (1969) Psychotropic effects of caffeine in man. IV. Quantitative and qualitative differences associated with habituation to coffee. Clin Pharmacol Ther 10(4):489-497

Griffiths RR, Mumford CK, (1995) Caffeine, A drug of abuse? In, Bloom FE, Kupfer DJ, editors. Psychopharmacology, The fourth generation in progress. Raven Press, New York, pp 1699-1713

Griffiths RR, Bigelow GE, Liebson IA (1986) Human coffee drinking, reinforcing and physical dependence producing effects of caffeine. J Pharmacol Exp Ther 239(2):416-425

Griffiths RR, Evans SM, Heishman SJ, Preston KL, Sannerud CA, Wolf B, Woodson PP, (1990) Low-dose caffeine discrimination in humans. J Pharmacol Exp Ther 252: 970-978

Guillet R, Dunham L, (1995) Neonatal caffeine exposure and seizure susceptibility in adult rats. Epilepsia $36: 743-749$

Gullberg El, Ferrell F, Christensen HD, (1986) Effects of postnatal caffeine exposure through dam's milk upon weanling rats. Pharmacol Biochem Behav. 24(6): 1695-1701

Hale KL, Hughes JR, Oliveto AH, Higgins ST (1995) Caffeine self-administration and subjective effects in adolescents. Exp Clin Psychopharmacol 3:364-370

Harnack L, Stang J, Story M (1999) Soft drink consumption among US children and adolescents, nutritional consequences. J Acad Nutr Diet 99(4):436-41

Harrison FE, Hosseini AH, MacDonald MP (2009) Endogenous anxiety and stress responses in water maze and Barnes maze spatial memory tasks. Behav Brain Res 198:247-251

Hasselmo ME, Bower JM (1993) Acetylcholine and memory. Trends Neurosci 16(6):218-22

Hogervorst E, Riedel WJ, Kovacs E, Brouns F, Jolles J (1999) Caffeine improves cognitive performance after strenuous physical exercise. Int J Sports Med 20:354-61 
Holloway WR (1982) Caffeine, effects of acute and chronic exposure on the behavior of neonatal rats. Neurobehav Toxicol Teratol 4:21-32

Howard MA, Marczinski CA (2010) Acute Effects of a Glucose Energy Drink on Behavioral Control. Exp Clin Psychopharmacol 18(6):553-561

Hughes JR, Hale KL (1998) Behavioral effects of caffeine and other methylxanthines on children. Exp Clin Psychopharmacol 6(1):87-95

Hughes JR, Oliveto AH, Liguori A, Carpenter J, Howard T (1998) Endorsement of DSM-IV dependence criteria among caffeine users. Drug Alcohol Depend 52(2):99-107

Hughes RN, Beveridge IJ (1990) Sex and age-dependent effects of prenatal exposure to caffeine on openfield behavior, emergence latency and adrenal weights in rats. Life Sci 47:2075-2088

Jarvis MJ (1993) Does caffeine intake enhance absolute levels of cognitive performance?

Psychopharmacology (Berl) 110:45-52

Johnson-Kozlow M, Kritz-Silverstein D, Barrett-Connor E, Morton D (2002) Coffee Consumption and Cognitive Function among Older Adults. Am J Epidemiol 156(9):842-850

Jones S, Fernyhough C (2009). High caffeine intake lead to hallucination proneness. Pers Individ Dif, $10.1016 / \mathrm{j}$.

Juárez-Méndez S, Carretero R, Martínez-Tellez R, Silva-Gómez AB, Flores G (2006) Neonatal caffeine administration causes a permanent increase in the dendritic length of prefrontal cortical neurons of rats. Synapse 60: 450-455

Kelly SP, Gomez-Ramirez M, Montesi JL, Foxe JJ (2008) L-Theanine and Caffeine in Combination Affect Human Cognition as Evidenced by Oscillatory alpha-Band Activity and Attention Task Performance. J Nutr 138:1572S-1577S

Kendler KS, Prescott CA (1999) Caffeine intake, tolerance, and withdrawal in women, a population-based twin study. American Journal of Psychiatry 156(2): 223-228

Kenemans JL, Lorist MM (1995) Caffeine and selective visual processing. Pharmacology Biochemistry and Behavior 52:461-471

Komada M, Takao K, Miyakawa T (2008) Elevated Plus Maze for Mice. J Vis Exp (22):e1088

Ledent C, Vaugeois JM, Schiffmann SN, Pedrazzini T, El Yacoubi M, Vanderhaeghen JJ, Costentin J, Heath JK, Vassart G, Parmentier M (1997) Aggressiveness, hypoalgesia and high blood pressure in mice lacking the adenosine A2a receptor. Nature 388(6643):674-678 
Li XD, He RR, Qin Y, Tsoi B, Li YF, Ma ZL, Kurihara H (2012) Caffeine Interferes Embryonic Development through Over-stimulating Serotonergic System in Chicken Embryo. Food Chem Toxicol 6517:1-6

Lieberman HR, Tharion WJ, Shukitt-Hale B, Speckman KL, Tulley R (2002) Effects of caffeine, sleep loss, and stress on cognitive performance and mood during U.S. Navy SEAL training. Sea-Air-Land.

Psychopharmacology (Berl). 164: 250-261

Lopez F, Miller LG, Greenblatt DJ, Kaplan GB, Shader RI (1989) Interaction of caffeine with the GABAA receptor complex, alterations in receptor function but not ligand binding. Eur J Pharmacol 172:453-459

Lopez-Cruz L, Salamone JD, Correa M (2013) The Impact of Caffeine on the Behavioral Effects of Ethanol Related to Abuse and Addiction, A Review of Animal Studies. J Caffeine Res 3 (1):9-21.

Lorenzo AM, León D, Castillo CA, Ruiz MA, Albasanz JL, Martín M (2010). Maternal caffeine intake during gestation and lactation down-regulates adenosine $A 1$ receptor in rat brain from mothers and neonates. $J$ Neurosci Res 88(6): 1252-1261 Doi, 10.1002/jnr.22287.

Mednick SC, Cai DJ, Kanady J, Drummond SP (2008) Comparing the benefits of caffeine, naps and placebo on verbal, motor and perceptual memory. Behav Brain Res 193(1): 79-86

Montandon G, Bairam A, Kinkead R (2006) Long-Term Consequences of Neonatal Caffeine on Ventilation, Occurrence of Apneas, and Hypercapnic Chemoreflex in Male and Female Rats. Pediatr Res 59:519-524

Mouzon B, Chaytow H (2012). Repetitive Mild Traumatic Brain Injury in a Mouse Model Produces Learning and Memory Deficits Accompanied by Histological Changes. J Neurotrauma 29 (18):27612773

Myhrer T (2003) Neurotransmitter systems involved in learning and memory on the rat, a meta-analysis based on studies of four behavioural tasks. Brain Res Rev 41:268-287

Nakamoto T, Roy G, Gottschalk SB, Yazdani M, Rossowska M (1991) Lasting effects of early chronic caffeine feeding on rats' behavior and brain in later life. Physiol Behav 49: 721-727

Nehlig A (1999) Are we dependent upon coffee and caffeine? A review on human and animal data. Neurosci Biobehav Rev 23: 563-576

Nehlig A, Debry G (1994) Consequences on the newborn of chronic maternal consumption of coffee during gestation and lactation, A review. J Am Coll Nutr 13(1):6-21

Nehlig A, Debry G (1994) Potential teratogenic and neurodevelopmental consequences of coffee and caffeine exposure, a review on human and animal data. Neurotoxicol Teratol 16(6):531-543

Nehlig A, Debry GJ (1994) Effects of coffee and caffeine on fertility, reproduction, lactation, and development. Review of human and animal data. J Gynecol Obstet Biol Reprod 23(3):241-256 
Nehlig A, Daval J, Debry G (1992) Caffeine and the central nervous system, mechanisms of action, biochemical, metabolic and psychostimulant effects. Brain Res Rev 17(2):139-170

Olini N, Kurth S, Huber R (2013) The Effects of Caffeine on Sleep and Maturational Markers in the Rat. PLoS One 8:e72539. doi, 10.1371/journal.pone.0072539

Park, JE (2016) An in vivo study of the effects of perinatal caffeine exposure on synaptic efficacy in the hippocampus of freely moving adult rats. Senior Theses, Trinity College, Hartford, CT. Trinity College Digital Repository, http://digitalrepository.trincoll.edu/theses/60

Pauldurai J (2014) The Effects of Selected Drugs on the Memory Recall of Sleep Deprived Mice. J Interdis Undergrad Res 6:3

Persad LAB (2011) Energy Drinks and the Neurophysiological Impact of Caffeine. Front Neurosci 5 (116):1- 8 Doi, 10.3389/fnins.2011.00116.

Rapoport JL, Berg CJ, Ismond DR, Zahn TP, Neims A (1984) Behavioural effects of caffeine in children. Relationship between dietary choice and effects of caffeine challenge. Arch Gen Psychiatry 41(11):10731079

Roca DJ, Schiller GD, Farb DH (1988) Chronic caffeine or theophylline exposure reduces gammaaminobutyric acid/benzodiazepine receptor site interactions. Mol Pharmacol 33 (5):481-485

Rogers PJ, Hohoff C, Heatherley SV, Mullings EL, Maxfield PJ, Evershed RP, Deckert, J, and Nutt D. J. (2010) Association of the Anxiogenic and Alerting Effects of Caffeine with ADORA2A and ADORA1 Polymorphisms and Habitual Level of Caffeine Consumption. Neuropsychopharmacology 35(9), 1973-1983 Doi 10.1038/npp.2010.71

Rudolphi KA, Keil M, Fastbom J, Fredholm BB (1989) Ischaemic damage in gerbil hippocampus is reduced following upregulation of adenosine $\left(A_{1}\right)$ receptors by caffeine treatment. Neurosci Lett 1039 (3), 275-280

Savoca MR, Evans CD, Wilson ME, Harshfield GA, Ludwig DA (2004) The association of caffeinated beverages with blood pressure in adolescents. Arch Pediatr Adolesc Med 158(5):473-477

Savoca MR, Mackey ML, Evans CD, Wilson M, Ludwig DA, Harshfield GA (2005) Association of ambulatory blood pressure and dietary caffeine in adolescents. Am J Hypertens 18(1):116-120.

Shi D, Nikodijević O, Jacobson KA, Daly JW (1993) Chronic Caffeine Alters the Density of Adenosine, Adrenergic, Cholinergic, GABA, and Serotonin Receptors and Calcium Channels in Mouse Brain. Cell Mol Neurobiol 13(3): 247-261

Silva CG, Métin C, Fazeli W, Machado NJ, Darmopil S, Launay BC (2013). Adenosine Receptor Antagonists Including Caffeine Alter Fetal Brain development in Mice. Sci Transl Med 5(197): 97-104 
DOI, 10.1126/scitransImed.3006258.

Silverman K, Evans S M, Strain E C, Griffiths RR (1992) Withdrawal syndrome after the double-blind cessation of caffeine consumption. N Engl J Med 327(16):1109-1114.

Smith A, Kendrick A, Maben A Salmon J (1994) Effects of breakfast and caffeine on cognitive performance, mood and cardiovascular functioning. Appetite 22:39-55.

Soellner DE, Grandys T, Nuñez JL (2009) Chronic Prenatal Caffeine Exposure Impairs Novel Object Recognition and Radial Arm Maze Behaviors in Adult Rats. Behav Brain Res 205(1):191-199

Strain EC, Mumford GK, Silverman K, Griffiths RR (1994) Caffeine dependence syndrome. Evidence from case histories and experimental evaluations. JAMA, 272(13):1043-1048

Sunyer B, Patil S, Höger H, Lubec G (2007). Barnes maze, a useful task to assess spatial reference memory in the mice. Journal name:

Tanaka H, Nakazawa K, Arima M (1987). Effects of maternal caffeine ingestion on the perinatal cerebrum. Biol Neonate 51(6):332-339

Tanaka H, Nakazawa K, Arima M Iwasaki S (1984) Caffeine and its dimethyl- xanthines and fetal cerebral development in rat. Brain Dev 6:355-361

Temple JL (2009) Caffeine Use in Children, What we know, what we have left to learn, and why we should worry. Neuroscience \& Biobehavioral Reviews. 33(6):793-806

Walf AA, Frye CA (2007) The use of the elevated plus maze as an assay of anxiety-related behavior in rodents. Nature Protoc 2(2): 322-328

Wentz CT, Magavi SSP (2009) Caffeine alters proliferation of neuronal precursors in the adults' hippocampus. Neuropharmacology 56:994-1000

Zahniser N, Simosky J, Mayfield RD, Negri C, Hanaia T, Larson A, Kelly MA, Grandy DK, Rubinstein M, Low MJ, Fredholm BB (2000) Functional Uncoupling of Adenosine A2a Receptors and Reduced Response to Caffeine in Mice Lacking Dopamine D2 Receptor. J Neurosci 20 (16):1

Zappettini S, Faivre E, Ghestem A, Carrier S, Buée L, Blum D, Esclapez M, Bernard C (2019) Caffeine Consumption During Pregnancy Accelerates the Development of Cognitive Deficits in Offspring in a Model of Tauopathy. Front Cell Neurosci 13: 438 https://doi.org/10.3389/fncel.2019.00438

Zielke CL, Zielke HR (1987) Chronic exposure to subcutaneously implanted methylxanthines. Differential elevation of A1-adenosine receptors in mouse cerebellar and cerebral cortical membranes. Biochem Pharmacol 36(15): 2533-2538 
Figures
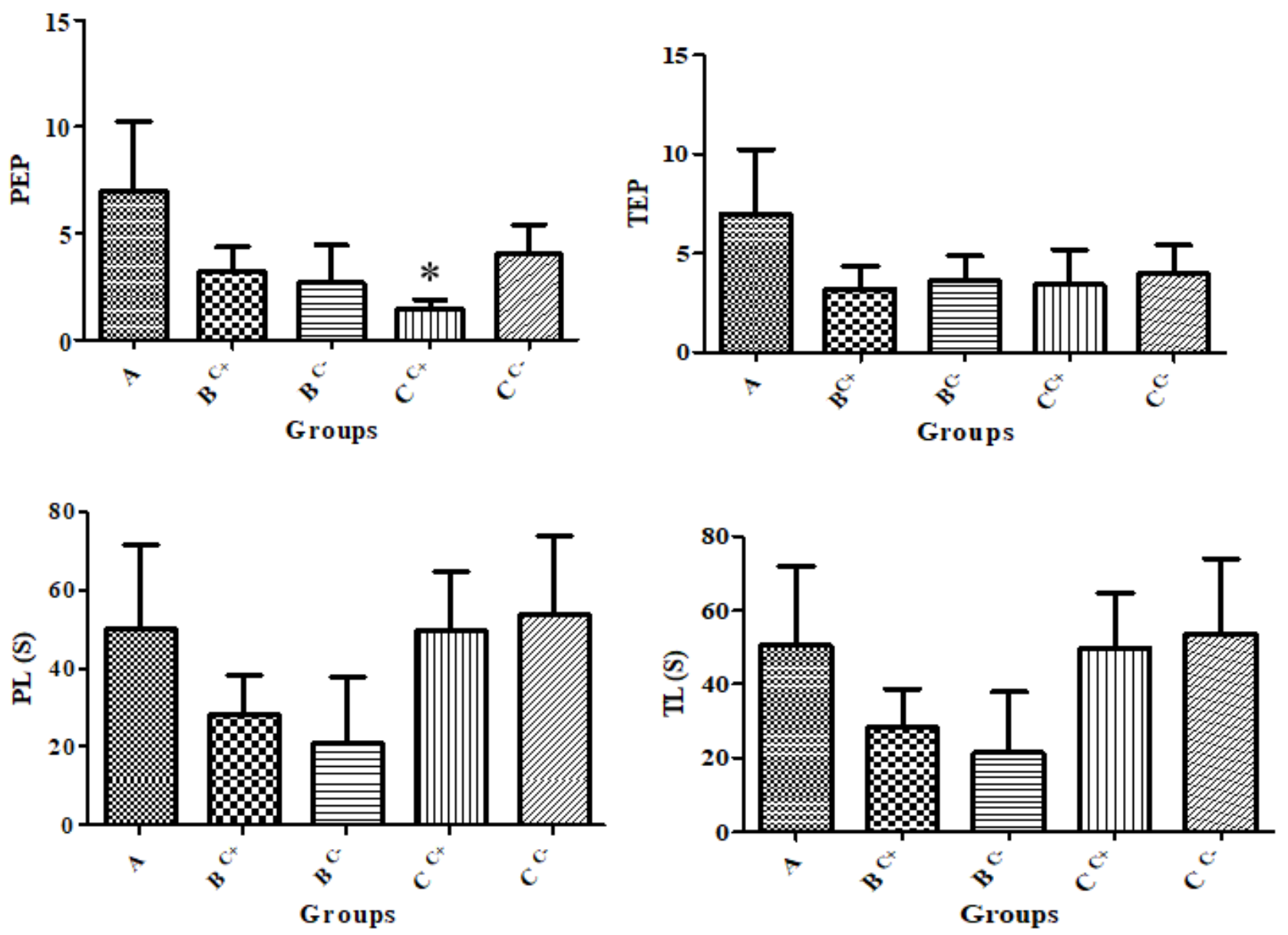

Figure 1

Barnes Maze Memory Test showing the Short-Term Memory parameters including the Primary Error Pokes [PEP]; Total Error Pokes [TEP]; Primary Latency [PL]; and Total Latency [TL]. * Indicates Statistical Significance $(P \leq 0.05)$ 

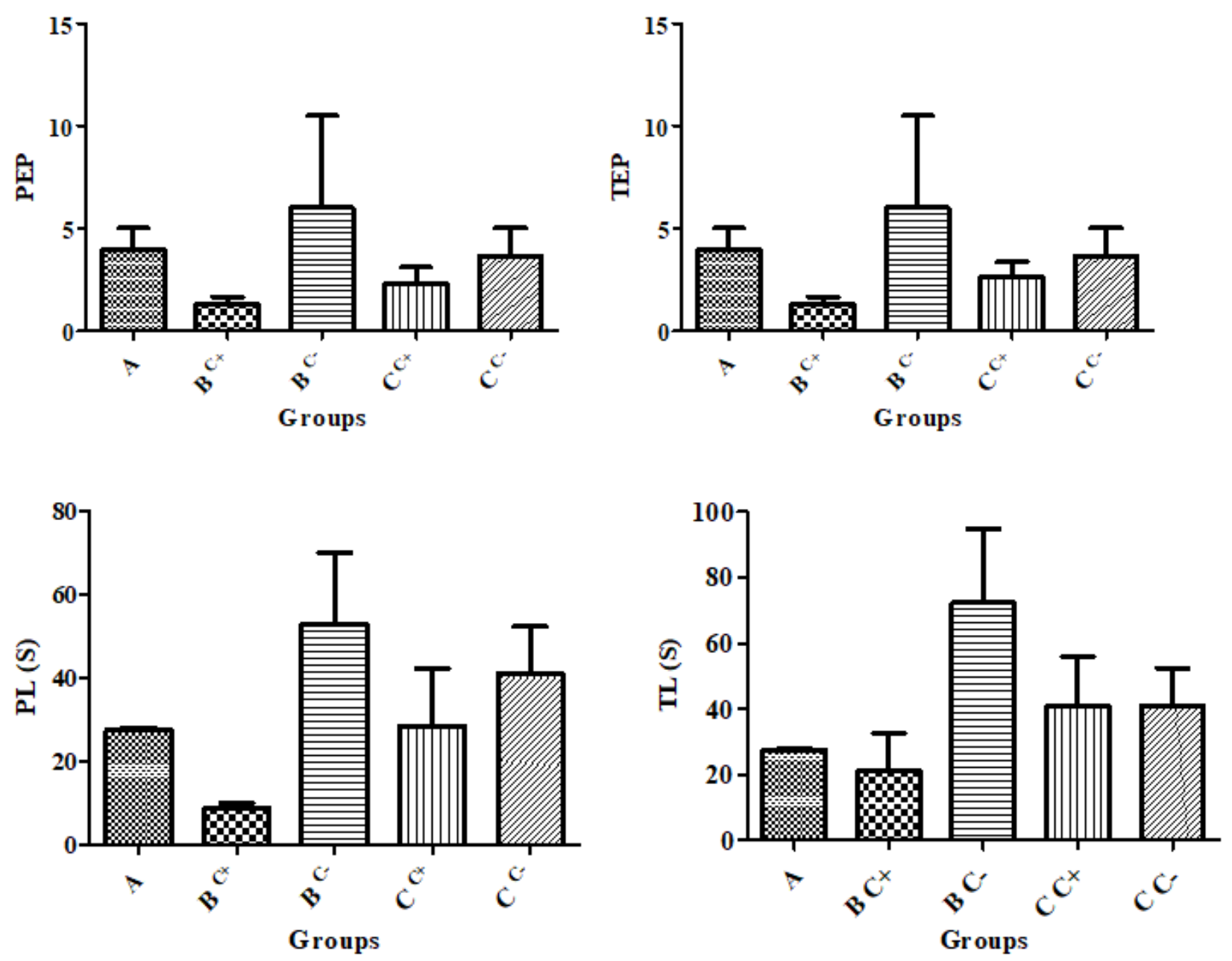

Figure 2

Barnes Maze Memory Test showing the Long-Term Memory parameters including the Primary Error Pokes [PEP]; Total Error Pokes [TEP]; Primary Latency [PL]; and Total Latency [TL]. Key: * Indicates Statistical Significance $(P \leq 0.05)$ 

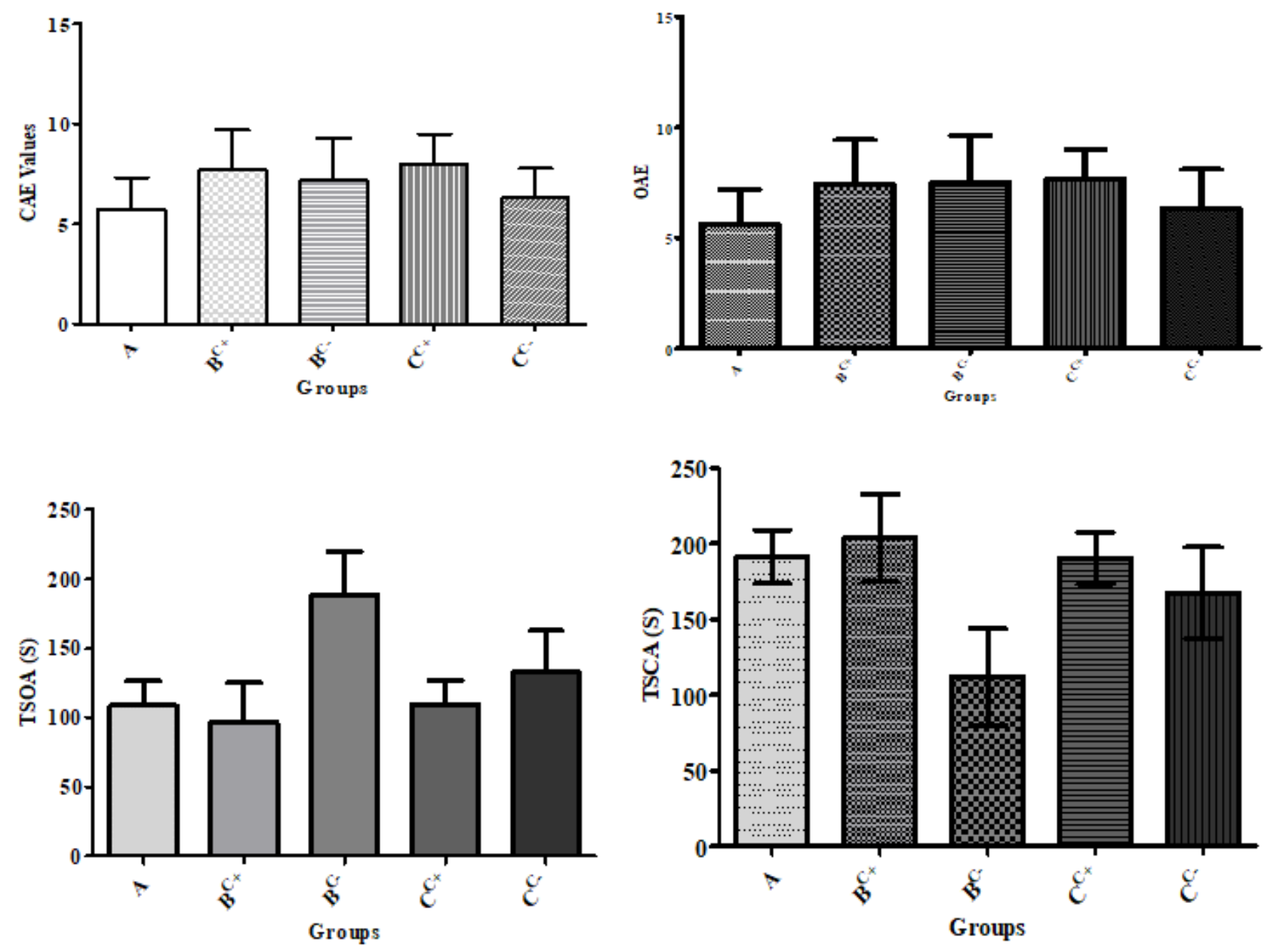

Figure 3

Elevated plus maze anxiety test parameters including Close Arm Entry [CAE]; Open Arm Entry [OAE]; Time Spent in Open Arm [TSOA] and Time Spent in Close Arm [TSCA]. Animals that were administered caffeine had higher Close Arm Entry (CAE) values when cpared wih the control (Group A) on the average. In each of the treated groups, the pre and postnatal-treated animals had higher CAE values than the prenataltreated groups $(-C)$. Caffeine mildly increased anxiety tendnency in the treated animal groups; but values of the CAE parameters were not statitistically significant. The animal groups that were administered caffeine all had their mean OAE values higher than the control, indicating increased inter-arms motor activities and movements relative to the control. This, though values were not statitiscally signiciant, showed slight herperactivity or anxiety tendencies. 

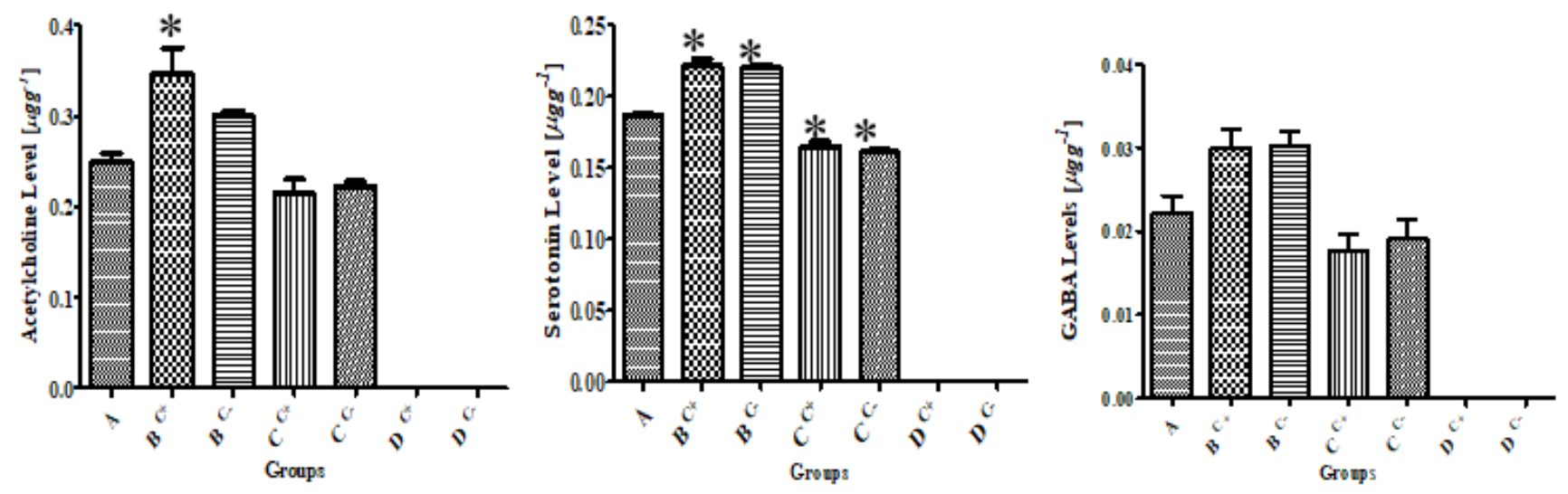

Figure 4

Level of nierotamitters levels in the prefrtal cortex brain tiisues including acetylcholine, serotonin and GABA (Y-Aminobutyric acid). Key: * Indicates Statistical Significance $(P \leq 0.05)$ 